\title{
Application of full factorial design to screen the factors influencing the wax deposition of Malaysian crude oil
}

\author{
Basem Elarbe $^{1} \cdot$ Ibrahim Elganidi $^{1} \cdot$ Norida Ridzuan $^{1}{ }^{10} \cdot$ Kamal Yusoh $^{1} \cdot$ Norhayati Abdullah $^{1}$. \\ Shamala Vijaya Kumar ${ }^{1}$
}

Received: 26 July 2021 / Accepted: 14 December 2021 / Published online: 20 December 2021

(c) The Author(s) 2021

\begin{abstract}
Wax deposition in production pipelines and transportation tubing from offshore to onshore is critical in the petroleum industry due to low-temperature conditions. The most significant popular approach to solve this issue is by inserting a wax inhibitor into the channel. This research aims to reduce the amount of wax formation of Malaysian crude oil by estimating the effective parameters using Design-Expert by full factorial design (FFD) method. Five parameters have been investigated, which are rotation speed (A), cold finger temperature (B), duration of experimental (C), the concentration of poly (stearyl acrylate-co-behenyl acrylate) (SABA) (D), and concentration of nano-silica $\mathrm{SiO}_{2}$ (E). The optimum conditions for reducing the amount of wax deposit have been identified using FFD at $300 \mathrm{rpm}, 10{ }^{\circ} \mathrm{C}, 1 \mathrm{~h}, 1200 \mathrm{ppm}$ and $400 \mathrm{ppm}$, respectively. The amount of wax deposit estimated is $0.12 \mathrm{~g}$. The regression model's variance results revealed that the $R^{2}$ value of 0.9876 , showing $98.76 \%$ of the data variation, can be described by the model. The lack of fit is not important in comparison to the pure error, which is good. The lack of fit $F$ value of 12.85 means that there is only a $7.41 \%$ probability that this huge can occur because of noise. The influence of cold finger temperature was reported as the main contributing factor in the formation of wax deposits compared to other factors. In addition, the interaction between factor $\mathrm{B}$ and factor $\mathrm{C}$ revealed the highest interaction effect on the wax deposition. In conclusion, the best interaction variables for wax inhibition can be determined using FFD. It is a valued tool to measure and detect the unique relations of two or more variables. As a result, the findings of this study can be used to develop a reliable model for predicting optimum conditions for reducing wax deposits and the associated costs and processing time.
\end{abstract}

Keywords SABA copolymer $\cdot$ Nano-silica $\cdot$ Operation factors $\cdot$ FFD analysis $\cdot$ Wax deposition

\section{Introduction}

The oil and gas industry is a well-established industry that serves a wide range of energy requirements (Wang et al. 2016). The wax deposition is one of the severe operational issues widespread in the petroleum industry, which changes the rheological characteristic of crude oil. The deposition of the wax layer on the inner curved surface area and the maintenance of oil pipelines or distribution networks alone is a tedious task. It is considered a complex and costly problem (Junyi and Hasan 2018; Sun et al. 2016). In Malaysia, the oil

Norida Ridzuan

norida@ump.edu.my

1 Author's Faculty of Chemical and Process Engineering Technology, Universiti Malaysia Pahang, 26300 Gambang, Pahang, Malaysia wells reportedly contained as high as $20 \mathrm{wt} . \%$ of solid wax content and temperature of pour point as high as $36^{\circ} \mathrm{C}$. Oil fields, such as Penara, Angsi, and Dulang, encounter critical wax deposition problem. These oil fields with a water depth of between 60 and $70 \mathrm{~m}$ have surface temperature of $34^{\circ} \mathrm{C}$ and average seabed temperature of about $25^{\circ} \mathrm{C}$ at the depth of $61 \mathrm{~m}$ (Lim et al. 2019). Therefore, the wax prediction is critical because the accumulation of wax in pipelines is a significant concern in the petroleum industry (Alnaimat and Ziauddin 2020). The cold temperature of the pipeline walls allows the wax molecules in the oil to crystallize over time in the subsea pipelines and accumulate on the inner surface. It may also result in a total blockage of the channel, affecting the supply (Alnaimat and Ziauddin 2020). In the cold region near the seabed, the fluid temperature can be reached to $5{ }^{\circ} \mathrm{C}$ while transporting crude oil. When crude oil temperature drops less than the wax appearance temperature, Wax starts 
to precipitate out from fluid and creates a three-dimensional network structure (Elganidi et al. 2020; Ridzuan et al. 2020c; Yao et al. 2018). The solubility of wax is influenced over time, and the rate of deposition rises, causing the operative flow area or pipeline cross-section area to decrease. This can also trigger a full pipe blockage that affects the supply (Chala et al. 2014; Junyi and Hasan 2018).

In the oil and gas industry, technology and different approaches have been used to solve the precipitation and deposition of waxes, which are mechanical, thermal, and chemical techniques or combinations of these techniques to solve wax deposition (Song et al. 2016; Yang et al. 2015). The use of chemicals to avoid wax deposition has been the focus of recent efforts. In order to disrupt the nucleation and adhesion of the wax particles, chemical inhibitors are injected into the well stream at the manifold header or the wellhead. There are four types of chemical inhibitors used to prevent wax precipitation: wax solvents, pour point depressants (PPDs), flow improvers or wax crystal modifiers, and wax dispersants (Ridzuan et al. 2020c; Yang et al. 2015). However, the use of polymeric pour point depressant is a new and convenient process. PPDs are primarily utilized to lower the WAT and pour point (PP), enhance the rheological characteristics of waxy oil, and significantly change the structure of wax crystal to prevent its aggregation. In addition, PPDs are extremely interracially effective polymers that alter the crystal's morphology and the crystal's interactions (Ridzuan et al. 2020c). Many types of chemical inhibitors may be utilized as PPDs to minimize waxy crude oil's wax deposition. The commonly utilized PPDs include the (EVA) ethylene-vinyl acetate copolymer (Machado et al. 2001; Ridzuan et al. 2020b; Tu et al. 2017), (POA) poly octadecyl acrylate (Handayani et al., 2019; Yang et al. 2018, 2015; Zhu et al. 2004), poly alkyl acrylate (Feng et al. 2014; Litvinets et al. 2016), poly (dodecyl methacrylate-co-vinyl acetate (Ghosh et al. 2017).

Recently, the use of nanoparticles in the petroleum industry has been studied. Nanohybrid PPD has also been confirmed to minimize the wax deposits produced, decrease the WAT, and remove wax accumulation chances as nanoparticles have greater steadiness, good adsorption, and good capacity for diffusion (Yang et al. 2015). In addition, the nanoparticle cost is smaller than most of the polymers used, so it is further economical and inexpensive (Sun et al. 2017). The use of nanoparticles has also proved practical because it offers a broader surface area that improves particle interaction with crude oil (Fakoya and Shah 2017). However, the impacts of blending nanoparticles with PPD on wax precipitation of waxy crude oil were undefined. Therefore, there were limited studies in this specific area that have been tested by Lim et al. (2018), Ridzuan et al. (2020c) and Subramanie et al. (2020).
Design software is a method that has been used effectively for experimental design (DOE). The program offers a feature identified as a full factorial design suitable for studying and evaluating the factors required in a process for several factors. A full factorial design is a more cooperative process that efficiently assesses the interaction between two or more independent variables in response (Öztürk and Kavak 2008; Ridzuan et al. 2016). This technique takes more than one factor at the same time into consideration and requires only a small number of experimental runs. Non-experts, nevertheless, favour (OFAT) one factor at a time, particularly in states where the data are inexpensive and abundant. This method, however, cannot be used simultaneously for all possible factor combinations.

Meanwhile, the design of OFAT is a conventional design in which just one variable can be altered at a time, whereas other variables are kept fixed. This method's weakness is that it is not possible to investigate the relationships between all the considered variables. Therefore, it is necessary to determine the effect of all possible variables on wax formation. A new-fangled technique to displace the OFAT approach should be tested to optimize the wax deposition that is affected by many independent factors. Because of the lack of understanding of the dominant variables contributing to wax deposition, it is essential to establish relationships between factors affecting wax deposition in the transport of oil. The relationship is predictable to expect the doubts of wax formation amount within the various range of experimental conditions and values (Ridzuan et al. 2016). Screening of full factorial design (FFD) is implemented to find the critical variables impacting a process. This method decreases the number of experiments without the request to run a considerable number of studies. FFD makes it possible to study the impact of several variables at the same time while preserving the consistency of data collection (Ridzuan et al. 2020a). According to Ridzuan et al. (2016), the factors that affect wax deposition have been screened using the FFD design. The research findings exhibited that a smaller amount of wax deposit was found $(0.75 \mathrm{~g})$ at the best conditions of EVA at $2 \mathrm{~h}$ of time, $5000 \mathrm{ppm}$ of concentration, $15{ }^{\circ} \mathrm{C}$ cold finger temperature, and without rotation speed. In addition, (Ridzuan and Al-Mahfadi 2017) have optimized the best factors obtained from screening in 2016, which were cold finger temperature and stirring rate. According to the study's conclusions, the wax deposit amount was reduced to $0.0095 \mathrm{~g}$ following the optimization. The amount of wax deposit decreased dramatically as the temperature and stirring rate increased at $400 \mathrm{rpm}$ and $19^{\circ} \mathrm{C}$, respectively.

In this study, the effect of operational factors, including rotation speed, cold finger temperature, duration of the experiment, inhibitor concentration, and nanoparticle concentration on the wax deposit, was calculated statistically by the design process of FFD. Consequently, this paper aims 
to study the variable that most affects wax deposition and evaluate and analyse the relationship between variables.

\section{Method}

\section{Materials}

In this research, (Stearyl acrylate-co-behenyl acrylate) copolymer (SABA) has been synthesized by and Elarbe et al. (2019). The nanoparticle used was silica dioxide particles $\left(\mathrm{SiO}_{2}\right)$ (purity 99\%) obtained from Sigma-Aldrich. Toluene (purity 99\%) also was obtained from Sigma-Aldrich. The crude oil sample was provided by the refinery of PETRONAS from the Kerteh, Terengganu, Malaysia. The physical characteristics of crude oil are described in Table 1. The method used in this study to analyse raw materials and viscosity was similar to those mentioned in our previous article, where a detailed explanation can be found (Elarbe et al. 2021).

\section{Preparation of SABA/ nanoparticle solution}

Three different concentrations of SABA copolymer, $800 \mathrm{ppm}, 1000 \mathrm{ppm}$, and $1200 \mathrm{ppm}$, were prepared by dissolving $0.08 \mathrm{~g}, 0.1 \mathrm{~g}$, and $0.12 \mathrm{~g}$ of SABA copolymer, respectively. Then, $100 \mathrm{~mL}$ of toluene (solvent) (for each concentration) at the constant stirring rate at $500 \mathrm{rpm}$ for 60 min to shape a steady and homogenous solution.

To prepare nano-silica particles $\mathrm{SiO}_{2}$ at $800 \mathrm{ppm}$ (stock solution), $0.08 \mathrm{~g}$ of the nano-silica particle $\mathrm{SiO}_{2}$ with $100 \mathrm{~mL}$ of toluene was weighed and dissolved (Toluene is used as a solvent in this study). The $\mathrm{SiO}_{2}$ solution was preheated to $80^{\circ} \mathrm{C}$ and stirred for $60 \mathrm{~min}$ at $500 \mathrm{rpm}$, followed by treatment with ultrasound in an ultrasonic bath (Ultrasonic bath FB15051, Fisherbrand) at $40{ }^{\circ} \mathrm{C}$ for $30 \mathrm{~min}$ to disperse the nano-silica completely and confirm homogeneousness solution (Lim et al. 2018; Paramashivaiah and Rajashekhar 2016). Then, the solution of $800 \mathrm{ppm}$ of $\mathrm{SiO}_{2}$ nanoparticles (stock solution) has been diluted to $600 \mathrm{ppm}$ and $400 \mathrm{ppm}$ by adding toluene for each concentration.

To prepare the copolymer/nanoparticles blend, SABA copolymer and nano-silica $\left(\mathrm{SiO}_{2}\right)$ have been prepared in a volume ratio of $3: 1$, that is, $3 \%(\mathrm{v} / \mathrm{v})$ of the $1200 \mathrm{ppm} \mathrm{SABA}$

Table 1 Physical characteristics of sample Malaysian crude oil

\begin{tabular}{lll}
\hline Characteristics & Method & Result \\
\hline Viscosity (mPa.s) at $35{ }^{\circ} \mathrm{C}$ & ASTM D445-06 & 6.30 \\
Pour point $\left({ }^{\circ} \mathrm{C}\right)$ & ASTM D-97 & 11 \\
API & ASTM D-4052 & 42.4 \\
WAT $\left({ }^{\circ} \mathrm{C}\right)$ & ASTM D-2500 & 28 \\
\hline
\end{tabular}

copolymer were blended with $1 \%(\mathrm{v} / \mathrm{v})$ of the $800 \mathrm{ppm}$ nanosilica $\left(\mathrm{SiO}_{2}\right)$. The amount of SABA copolymer and nano-silica $\left(\mathrm{SiO}_{2}\right)(\mathrm{v} / \mathrm{v} \%)$ have been added to samples of crude oil at constant weight with observance to the total amount of crude oil in every run $(300 \mathrm{~mL}=250.3 \mathrm{~g})$. The SABA copolymer/ $\mathrm{SiO}_{2}$ nanoparticle blend has been stirred at $40{ }^{\circ} \mathrm{C}$ for $30 \mathrm{~min}$ before being injected into the cold finger vessel.

\section{Analysis of cold finger}

$300 \mathrm{~mL}$ of crude oil sample was heated over the WAT through thermal behaviour in an oven for $60 \mathrm{~min}$ to dissolve the wax of precipitate and remove any thermal history before being added into the stainless-steel vessel and to find a homogeneous mixture.

Figure 1 illustrates the cold finger apparatus system. To run the experiment, the sample of crude oil was placed at a fixed temperature of $50{ }^{\circ} \mathrm{C}$, the temperature of the cold finger was set within the range of 5 to $10^{\circ} \mathrm{C}$, experimental duration was set for 1 to $3 \mathrm{~h}$, the rotation speed of impeller was varied from 100 to $300 \mathrm{rpm}$, SABA copolymer concentrations was set within the range of 800 to $1200 \mathrm{ppm}$, while nano-silica $\left(\mathrm{SiO}_{2}\right)$ concentrations ranged from 400 to $800 \mathrm{ppm}$. A $10 \mathrm{~mL}$ (3:1) of SABA copolymer/nano-silica $\left(\mathrm{SiO}_{2}\right)$ blend was injected into the vessel for each run. The experimental runs were replicated three times to get exact data, and the results were averaged. At the end of every experimental run, the wax precipitate was scrapped off from a tube of cold finger and weighed for further examination. The response of the design experiment was evaluated with a Design-Expert to determine the effects of each variable involved. As shown in Table 3, the experimental runs were conducted by the Design-Expert's standard order series.

\section{Design of experiment}

Design-Expert software version 7.1.6 (State-Ease, USA) was used in this study. The factors screening was carried out using a half fractional factorial design (FFD) to identify the best contributing factors to reduce wax deposition and determine the interactions between factors that significantly affect wax deposit. Moreover, it can also remove the nonsignificant factors in the method and provide an effective and efficient design, especially in a limited material resource. In this design, five factors have been evaluated, which are speed of rotation (A), the temperature of the cold finger (B), duration of experiment (C), SABA concentration (D) and concentration of nano-silica (E) to minimize wax deposit. Table 2 shows the design factors and their levels, where low and high levels imply the lowest and highest range of the factors.

A half $\left(2^{4}\right)$ two level-five-factor design consisting of 19 experiments was presented for all the variables. Each

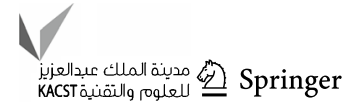




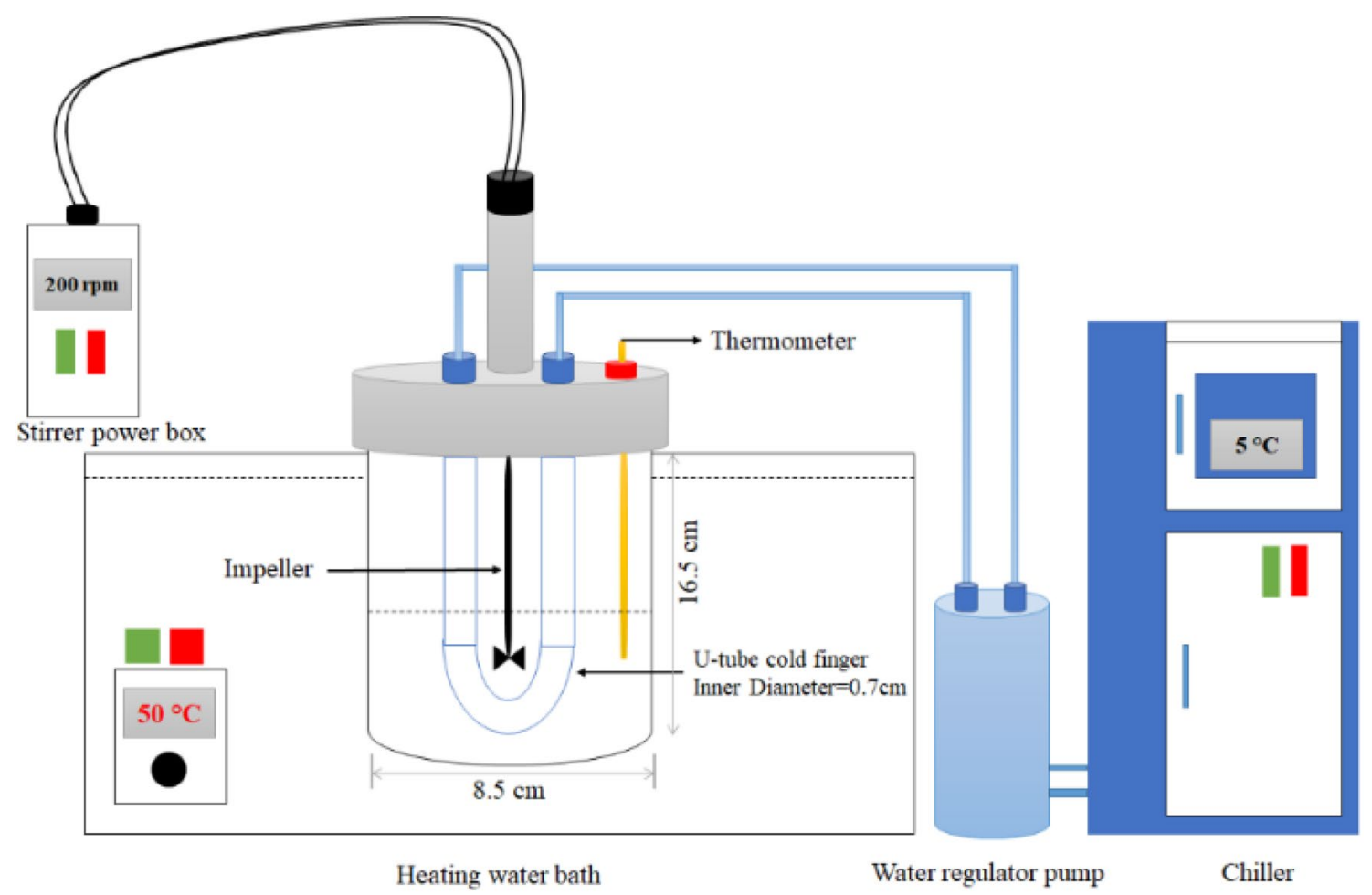

Fig. 1 The cold finger apparatus system

Table 2 Values of the factors examined in FFD for lower $(-1)$ and higher $(+1)$

\begin{tabular}{|c|c|c|c|}
\hline Factors & Code & Low level $(-1)$ & High level $(+1)$ \\
\hline Speed of rotation (rpm) & A & 100 & 300 \\
\hline $\begin{array}{l}\text { Cold finger temperature } \\
\left({ }^{\circ} \mathrm{C}\right)\end{array}$ & B & 5 & 10 \\
\hline Experimental duration (h) & $\mathrm{C}$ & 1 & 3 \\
\hline $\begin{array}{l}\text { Inhibitor concentration } \\
\quad(\mathrm{ppm})\end{array}$ & $\mathrm{D}$ & 800 & 1200 \\
\hline $\begin{array}{l}\text { Nano-silica concentration } \\
(\mathrm{ppm})\end{array}$ & $\mathrm{E}$ & 400 & 800 \\
\hline
\end{tabular}

matrix row represents one run in a given state, with three experimental repeats for the centre points to obtain accurate results, as shown in Table 3. The experiments sequence was randomized to decrease the systematic bias of uncontrolled variables. The optimum factors of the extraction process will then be used in the optimization studies using Central Composite Design (CCD).

FFD evaluated the experimental data to fit the following first-order polynomial equation. (Eq. (1)):

$Y=\beta 0+\sum_{i=1}^{n} \beta i X i$ where $Y$ signifies the response value, $\beta 0$ is the fixed coefficient, $\beta i$ represents the coefficient of linear factors, $n$ is the number of factors, and $X i$ denotes the coefficient of independent factors.

Table 3 demonstrates the experimental design model and the response (wax deposit) for the five factors and 19 empirical runs created.

\section{Results}

\section{Variance analysis (ANOVA)}

The purpose of the variance analysis ANOVA is to investigate which process factors significantly affect the wax deposition. The $F$ values may be verified by regression equation statistics, whereas the $P$ values are utilized to determine the importance of each coefficient. Table 4 shows that the $F$ value is 89.61 , and the $\mathrm{P}$ value is $P<0.0001)$. Because of noise, there was just a 0.01 per cent chance that this big model $F$ value would occur. Typically, the higher the calculated $F$ value, often connected to the tabularized value, implies a good model. The lower $P$ values display the more significance of the corresponding factor. 'Prob $>F$ ' values lower than 0.05 indicate that the model's design is very significant. In this study, A, B, C, D, E, BC, BD, CD were statistically significant model terms impacting wax deposit. On 
Table 3 Screening model experimental data in accordance with the standard order

\begin{tabular}{|c|c|c|c|c|c|c|c|}
\hline \multirow[t]{2}{*}{ Standard no. } & \multicolumn{6}{|c|}{ Factors } & \multirow{2}{*}{$\begin{array}{l}\text { Response } \\
\text { Wax deposit (g) }\end{array}$} \\
\hline & A & B & & $\mathrm{C}$ & $\mathrm{D}$ & $\mathrm{E}$ & \\
\hline 1 & 100 & 5 & 1 & & 800 & 800 & 0.72 \\
\hline 2 & 300 & 5 & 1 & & 800 & 400 & 0.67 \\
\hline 3 & 100 & 10 & 1 & & 800 & 400 & 0.27 \\
\hline 4 & 300 & 10 & 1 & & 800 & 800 & 0.35 \\
\hline 5 & 100 & 5 & 3 & & 800 & 400 & 0.78 \\
\hline 6 & 300 & 5 & 3 & & 800 & 800 & 0.75 \\
\hline 7 & 100 & 10 & 3 & & 800 & 800 & 0.66 \\
\hline 8 & 300 & 10 & 3 & & 800 & 400 & 0.62 \\
\hline 9 & 100 & 5 & 1 & & 1200 & 400 & 0.68 \\
\hline 10 & 300 & 5 & 1 & & 1200 & 800 & 0.65 \\
\hline 11 & 100 & 10 & 1 & & 1200 & 800 & 0.23 \\
\hline 12 & 300 & 10 & 1 & & 1200 & 400 & 0.12 \\
\hline 13 & 100 & 5 & 3 & & 1200 & 800 & 0.62 \\
\hline 14 & 300 & 5 & 3 & & 1200 & 400 & 0.54 \\
\hline 15 & 100 & 10 & 3 & & 1200 & 400 & 0.28 \\
\hline 16 & 300 & 10 & 3 & & 1200 & 800 & 0.23 \\
\hline 17 & 200 & 7.5 & 2 & & 1000 & 600 & 0.44 \\
\hline 18 & 200 & 7.5 & 2 & & 1000 & 600 & 0.45 \\
\hline 19 & 200 & 7.5 & 2 & & 1000 & 600 & 0.46 \\
\hline
\end{tabular}

*Speed of rotation (A), the temperature of the cold finger (B), duration of experiment $(\mathrm{C})$, SABA concentration (D), and concentration of nano-silica (E)

Table 4 Variance Analysis (ANOVA)

\begin{tabular}{lllllll}
\hline Source & Sum of squares & $d f$ & Mean square & $F$ value & $P$ value Prob $>F$ & Significant \\
\hline Model & 0.73 & 8 & 0.092 & 89.61 & $<0.0001$ & 0.8 \\
A & $6.0 \mathrm{E}-003$ & 1 & $6.0 \mathrm{E}-003$ & 5.88 & 0.0383 & 58.46 \\
B & 0.44 & 1 & 0.44 & 429.66 & $<0.0001$ & 5.20 \\
C & 0.039 & 1 & 0.039 & 38.18 & 0.0002 & 17.99 \\
D & 0.14 & 1 & 0.14 & 132.21 & $<0.0001$ & 0.52 \\
E & $3.9 \mathrm{E}-003$ & 1 & $3.9 \mathrm{E}-003$ & 3.82 & 0.0822 & 6.01 \\
BC & 0.045 & 1 & 0.045 & 44.20 & $<0.0001$ & 3.10 \\
BD & 0.023 & 1 & 0.023 & 22.77 & 0.0010 & Significant \\
CD & 0.041 & 1 & 0.041 & 40.14 & 0.0001 & Not significant \\
Curvature & $9.2 \mathrm{E}-003$ & 1 & $9.2 \mathrm{E}-003$ & 9.09 & 0.0146 & \\
residual & $1.8 \mathrm{E}-003$ & 9 & $1.02 \mathrm{E}-003$ & & & \\
Lack of fit & $1.6 \mathrm{E}-003$ & 7 & $1.28 \mathrm{E}-003$ & 12.85 & 0.0741 & \\
Pure error & $2.0 \mathrm{E}-003$ & 2 & $1.0 \mathrm{E}-003$ & & & \\
Cor total & 0.75 & 18 & & & & \\
$R^{2}$ & 0.9876 & & & & & \\
Adj- $R^{2}$ & 0.9766 & & & & & \\
Pred- $R^{2}$ & 0.9368 & & & & & \\
\hline
\end{tabular}

the other hand, the contribution values less than 0.10 imply that the design of model terms is not important. If there are several unimportant model terms, the model reduction can enhance your model. The Lack of fit is not important in comparison with the pure error, which is good. Consequently, it shows that the design of the model adequately fits the result well. The Lack of fit $F$ value of 12.85 means that there is only a $7.41 \%$ probability that this huge can occur because of noise. 
The study of the regression model's variance (ANOVA) in Table 4 detected the value of $R^{2}$ was 0.9876 , representing that the model can be clarified $98.76 \%$ of the data variation. In contrast, just $0.24 \%$ of the overall differences were not described by the model, which suggests that the design of the model fits well with the experimental and expected values. For a suitable model, the value of $R^{2}$ must not be less than 0.8, especially in the chemical field (Le Man et al. 2010). Nevertheless, (Koocheki et al. 2009) posited that a significant value of $R^{2}$ does not continuously indicate that regression design is perfect. Such a suggestion only could be made depending on a similarly great value of adj $R^{2}$. The value of the estimation coefficient adjusted is Adj $R^{2}=0.9766$. Thus, this signifies that the model is significantly, confirming that the agreement was good among the experimental and expected wax deposit values. According to Rai et al. (2016) (Rai et al. 2016), the adjusted $R^{2}$ and expected $R^{2}$ must be within $20 \%$ to be in great agreement. This condition is satisfied in this analysis with an expected $R^{2}$ value of 0.9368 . Thus, this model offers $93.68 \%$ variability in the prediction wax deposit beyond the experimental range of process conditions. In terms of coded factors, the final equation was calculated as follows:

$$
\begin{aligned}
\text { Wax deposit }= & +0.51-0.019 * \mathrm{~A}-0.17 * \mathrm{~B}+0.049 * \mathrm{C} \\
& -0.092 * \mathrm{D}+0.016 * \mathrm{E}+0.053 * \mathrm{~B} * \mathrm{C} \\
& -0.038 * \mathrm{~B} * \mathrm{D}-0.051 * \mathrm{C} * \mathrm{D}
\end{aligned}
$$

\section{The main and interaction impacts of variables}

Figure 2a-e shows the tendency of primary impacts plots when the level of variables is different. The two points were found in the plot at low and high levels from the experimental runs. For the total individual impact, these plots showed that factors $\mathrm{B}+, \mathrm{C}-$, and $\mathrm{D}+$ had the lowest amount of wax deposit contrasted with $\mathrm{A}-, \mathrm{A}+, \mathrm{B}-, \mathrm{C}+$, $\mathrm{D}-, \mathrm{E}-$, and $\mathrm{E}+$. The main effects were calculated by variables with steeper slopes, which would significantly affect the data experimentally. Then, the influence of variable B, the temperature of the cold finger, has been established as the primary contributor variable compared to other variable impacts.

\section{Effect of rotation speed on the wax deposition}

This percentage of rotation effect contribution was $0.8 \%$, indicating that the wax deposit factor increased slightly as the speed rotation increased. Once the optimum rotation speed has been exceeded, the amount of wax in the crude oil reduces. Nevertheless, the process is the same at a low rate of rotation, where the wax deposits slightly decreased at $300 \mathrm{rpm}$. Figure 2a depicts a rotation speed range of 100 to $300 \mathrm{rpm}$, and it was found that the impact of rotation speed has a critical role in reducing wax deposit because it has a contrary interaction with the wax deposit amount. This is proportional to most of the findings mentioned in the literature that express that wax deposits can be reduced with the increase in rotation speed (Salam et al. 2014). This finding may be clarified based on viscous drag, which rises as fluid velocity increases. Viscous drag is a resistance force to the fluid flow, which rises according to fluid dynamics with increasing speed (Municchi et al. 2020). If the deposited wax's shear stress is surpassed, the force tends to weaken the wax deposition layer or even destroy the deposited wax. This phenomenon has been due to various reasons related to the fluid's shear thickening behaviour resulting from a highly viscous liquid (Gürgen 2020), the difference in the

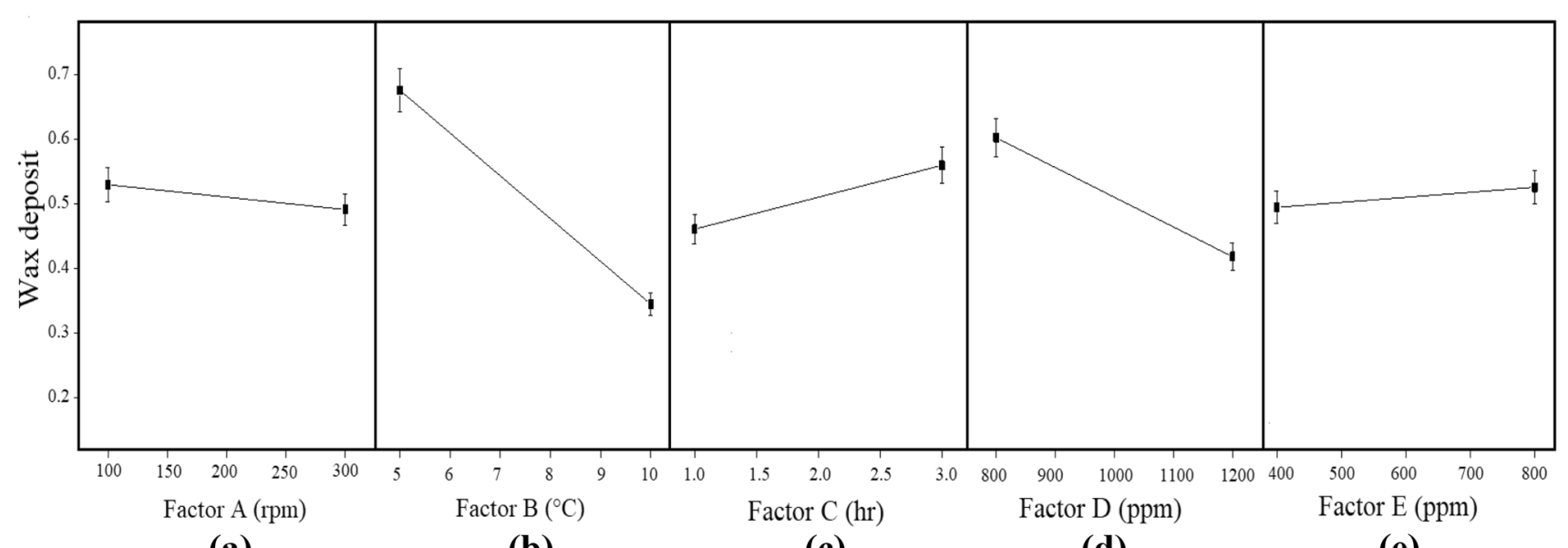

(a)

(b)

(c)

(d)

(e)

Fig. 2 Main impacts plots of a speed of rotation, A; b temperature of the cold finger, B; c duration of the experiment, C; $d$ concentration of $\mathrm{SABA}, \mathrm{D}$ and e concentration of $\mathrm{SiO} 2$, $\mathrm{E}$ on the wax deposition 
shear's untreated wax deposit, the quantity of fluid in the wax deposits, and the effect of viscosity on the cold finger that surrounds it. The ability of wax to deposit from the fluid and shape waxes is lower at the lower shear force (Subramanie et al. 2020). The comparison of wax deposit physical appearance at various rotation speeds is shown in Fig. 3. Whereas the shear force increased, the deposit of wax declined.

\section{Effect of cold finger temperature on the wax deposition}

The temperature of the cold finger with a percentage of 58.46 has been investigated. It implies that wax deposition is strongly influenced by temperature. Figure $2 b$ indicates that the maximum amount of wax deposit was found at $5{ }^{\circ} \mathrm{C}$ due to the propensity of wax molecules to shape wax crystals at lower temperatures of WAT. The temperature differential (T) between the bulk of the fluid sample and the cold finger's surface tends to produce more hard crude oil (Zhang et al. 2021). Furthermore, higher $T$ values lead to an increased wax deposit rate. The cold finger's temperature was set under the WAT value to measure the temperature influence on wax deposition rate (Fan et al. 2021; Mehrotra et al. 2020).

Consequently, the wax molecules adhere to one another easily at low temperatures and precipitate on cold finger surfaces. The comparison of wax deposit physical appearance at various temperatures is revealed in Fig. 4. For instance, at wax deposit weight of about $0.67 \mathrm{~g}$ at the lowest temperature of $5{ }^{\circ} \mathrm{C}$, the wax deposit was found to be thick and rough, precipitated all over the cold finger surface. In contrast, this amount falls to $0.34 \mathrm{~g}$ when the temperature difference rises to $5^{\circ} \mathrm{C}$; the cold finger has very low amounts of wax, and a much softer and thinner deposit of wax at $10^{\circ} \mathrm{C}$ is observed.

This finding is in complete accordance with previous studies conducted by (Lim et al. 2018; Ridzuan et al. 2016; Subramanie et al. 2020). However, the experiment does not support that the deposition of wax would increase with an increasing temperature differential between cool pipe wall temperature and the fluid temperature as described by (Jennings and Weispfennig 2005). However, As long as the
Fig. 3 Effect of the rotation speed of impeller on the wax deposition, a $100 \mathrm{rpm}$ and $\mathbf{b}$ $300 \mathrm{rpm}$

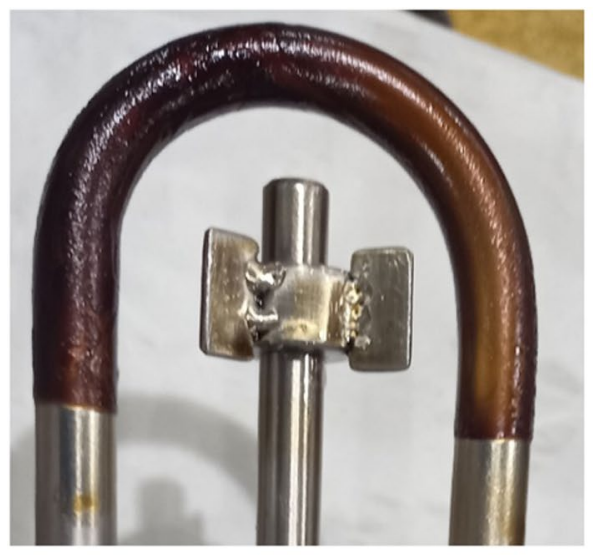

(a)

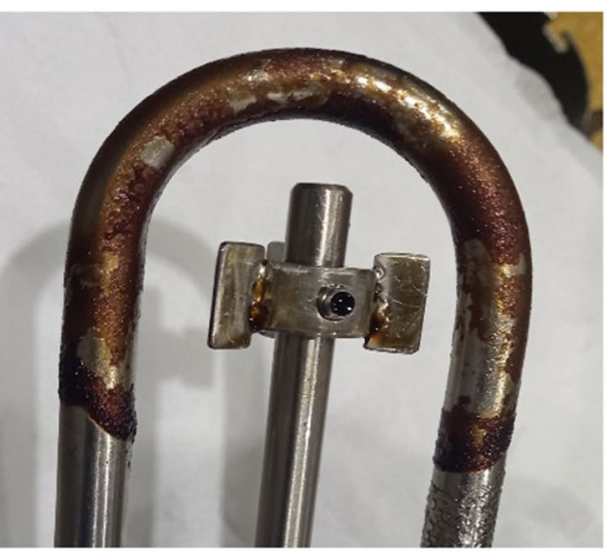

(b)
Fig. 4 Cold finger temperature effect on the deposition of wax, a $5{ }^{\circ} \mathrm{C}$ and $\mathbf{b} 10^{\circ} \mathrm{C}$

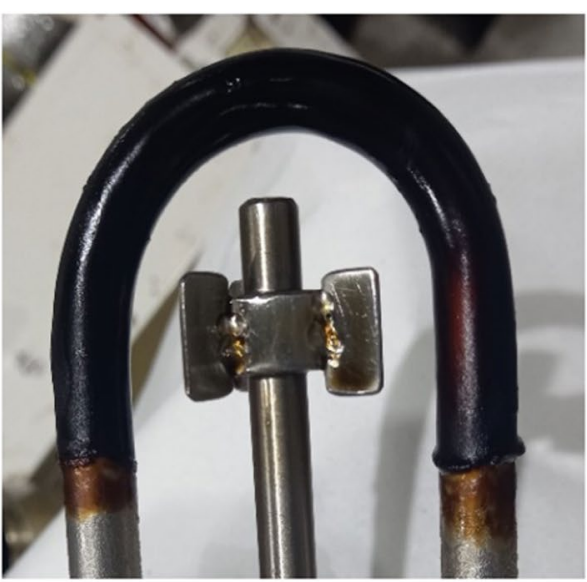

(a)

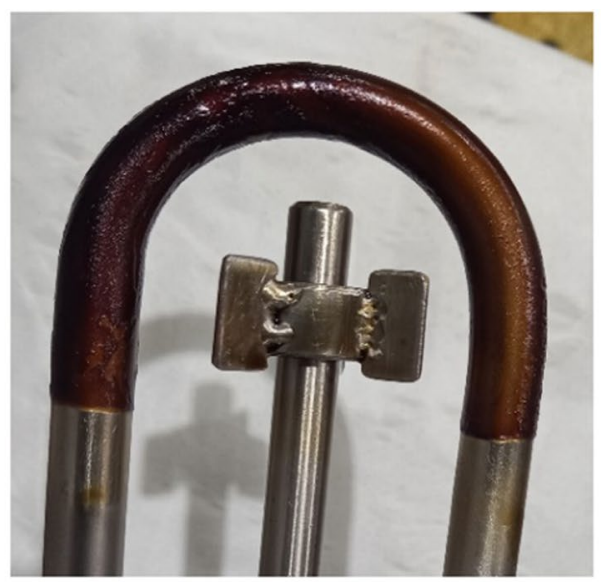

(b) 
operating temperature remains above the WAT, the wax deposition will never occur.

\section{Effect of experimental duration on the wax deposition}

The third significant variable affecting the precipitation of wax is the duration of the experiment, with the ratio of contribution being $5.20 \%$. More deposits on the surface of the cold finger were found after $3 \mathrm{~h}$ of experiment in contrast to $1 \mathrm{~h}$, as exhibited in Fig. 2c. The maximum amount of wax at $3 \mathrm{~h}$ was $0.56 \mathrm{~g}$, while the lowest was $0.46 \mathrm{~g}$ at $1 \mathrm{~h}$. The growth of crystal wax continues to increase as wax deposition occurs at temperatures lower than WAT. This result is supported by (Lim et al. 2018; Ridzuan et al. 2016).

The wax deposit that had accumulated on the tube surface of the cold finger after $3 \mathrm{~h}$ seemed to be stronger and in a rough shape. This process occurred because of the residence time. Experimental appearances of wax accumulated on residence time is illustrated in Fig. 5. Wax deposition has been observed to increase with increasing residence time. The residence time allows for more significant temperature loss and contributes to a lower oil temperature, resulting in the precipitation of the wax on the wall of the pipeline. Since this experiment has been carried out in the apparatus of cold finger, there is no continuous flow of fluid sample, resulting in a reduction in precipitation of the wax over a longer time of residence. It was concluded that at a maximum level of residence duration because the layers of precipitated wax provide heat insulation. (Lim et al. 2018; Mehrotra et al. 2020).

Similar results have been obtained further to confirm this obtained finding, (Ridzuan et al. 2016) even though their experiments were performed at a longer time value. These results are in agreement with other researchers (Junyi and Hasan 2018; Lim et al. 2018; Salam et al. 2014). However, it should be remembered that this scenario may not be implemented in a realistic oil field pipeline since the reservoir provides fresh crude oil constantly due to the fluid's shorter residence period.

\section{Effect of SABA concentration/SiO2 concentration on the wax deposition}

It is known that the wax inhibitor is one of the essential factors that affect wax deposition by changing the morphology of wax crystal, therefore improving crude oil flowability. In addition, nanoparticles further improve the behaviour of wax crystallization and reduce the structural strength of waxy crude oil at minimum temperature. The addition of the nanoparticle to the PPD plays a notable role in changing the solubility of the wax crystals in the fluid (Makwashi et al. 2021; Vakili et al. 2021; VijayaKumar et al. 2021). Further studies have been performed to obtain the optimum concentration combination for the wax inhibitor selected. SABA copolymer and nano-silica $(\mathrm{SiO} 2)$ have been prepared at a fixed volume ratio of $3: 1(\mathrm{v} / \mathrm{v})$. Malaysian crude oil was investigated at 800,1000 , and $1200 \mathrm{ppm}$ of SABA and blended with $\mathrm{SiO}_{2}$ nanoparticles at 400, 600, and $800 \mathrm{ppm}$.

The combination of $1200 \mathrm{ppm}$ of SABA and $400 \mathrm{ppm}$ of $\mathrm{SiO} 2$ nanoparticles was found to be an optimum concentration for wax deposition. The physical appearance of wax accumulated under optimum conditions is shown in Fig. 6. It was noted that this concentration has a thin layer on the surface of the tube and has fragile properties in contrast to the 800 ppm SABA sample, which had been observed to be in a harsh gel shape. For $\mathrm{SiO} 2$ nanoparticles, the hardness of wax deposits and the amount of wax deposit could not be reduced by increasing the concentration to $800 \mathrm{ppm}$. In this situation, the concentration should not be more than $400 \mathrm{ppm}$. Therefore, it was concluded that the $400 \mathrm{ppm}$ of nano-silica suggested was sufficient for the mitigation of wax precipitation. The experimental plot of deposited has been consistent with the data given in Fig. 2e.
Fig. 5 Effect of experimental duration on the wax deposition, a $1 \mathrm{~h}$ and $\mathbf{b} 3 \mathrm{~h}$

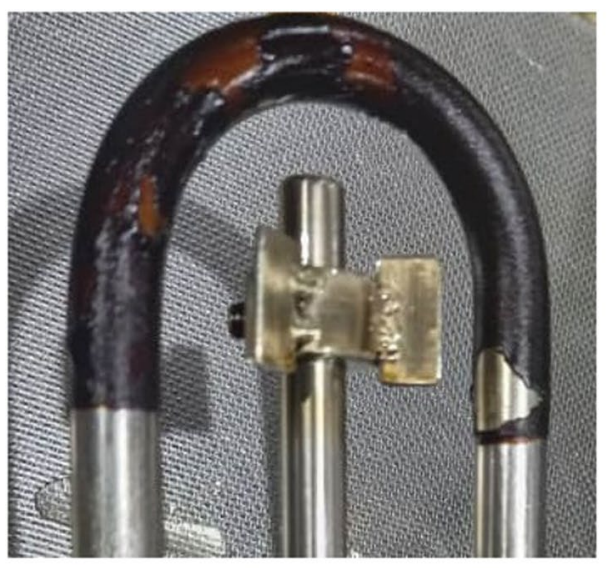

(a)

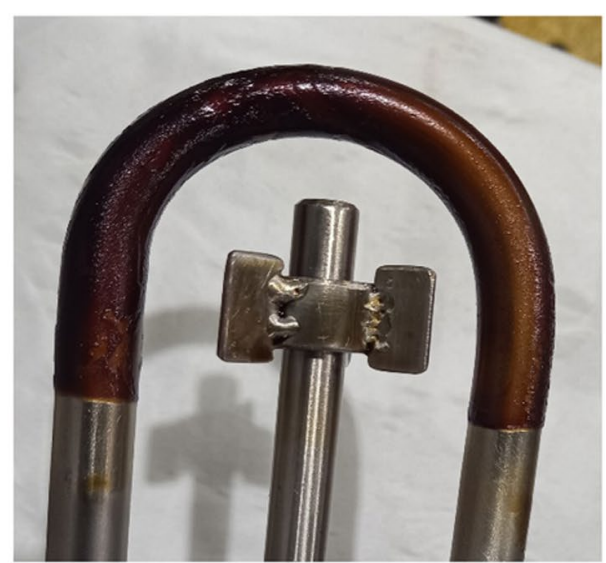

(b) 


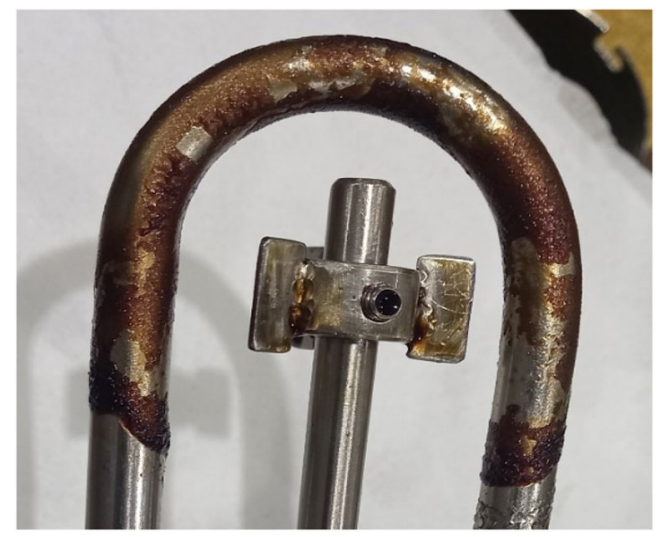

Fig. 6 Effect of SABA/SiO2 blend concentration on wax deposition

Moreover, it is also worth mentioning that the wax deposit weight does not alter dramatically with a rise to 800 ppm of nano-silica concentration $\mathrm{SiO} 2$. In this situation, reducing wax deposits with the highest concentration of $\mathrm{SiO} 2$ nanoparticles is not suitable. It is found that the optimal concentration dosage level and nanoparticle concentration does not increase over $400 \mathrm{ppm}$ for inhibition impact due to $\mathrm{SiO} 2$ nanoparticles act as further suspended particles and worsen crude oil flowability, which can finally lead to more wax deposition. The findings showed that the amount of wax deposit decreases once the optimum concentration is reached and the inhibition begins to deteriorate. In addition, it alters the crystallization of wax, impeding growing wax deposition by as long as most of the structures overlap and combine with the wax crystal brink. Meanwhile, various concentrations of PPD can be affected by the van der Waals interaction between crystals of wax in the fluid, which principally sets the crystallinity of wax in crude oil (Li et al. 2021; VijayaKumar et al. 2021).

\section{Interactions between factors on wax deposit}

When the key effects have been identified for each factor, the identification of how various factors interact to influence the results is then pursued. An interaction occurs when, depending on a second factor, one factor impacts the results differently.

The interaction (or two-way effects) of important factors over a significant level of 0.5 per cent is shown in Fig. 7 . If the lines are parallel, no interaction effect is considered. However, if the variations in the slopes are greater, the most critical interaction effect arises. The y-axis for the combination of each factor is always the same for studying these results.

The wax deposit interaction graph between cold finger temperature (B) and experimental duration $(\mathrm{C})$ is shown in Fig. 7a. The highest interaction effect was demonstrated by $\mathrm{BC}$ interaction, contributing just $6.01 \%$ to wax deposition. The amount of wax deposit at $\mathrm{C}-(1 \mathrm{~h})$ and $\mathrm{C}+(3 \mathrm{~h})$ were decreased once the cold finger temperature is extended until at $10^{\circ} \mathrm{C}$. It is noted that there is a greater impact of $\mathrm{B}$ when $\mathrm{C}$ is at $1 \mathrm{~h}$. Also, the interaction of $\mathrm{BC}$ demonstrates that the effect of B is steeper than C- when the data is restricted to $\mathrm{C}+$. In this research, however, the aim is to reduce wax precipitates compared to high wax precipitates. Therefore, the best range based on the objective is C-. Compared to other variables, this interaction may occur because both variables contribute most to wax deposition. The temperature of the cold finger variable contributes to the faster growth of wax crystals at $\mathrm{B}-$ than $\mathrm{B}+$ because it occurs under the pour point. However, the amount of wax deposit becomes more if

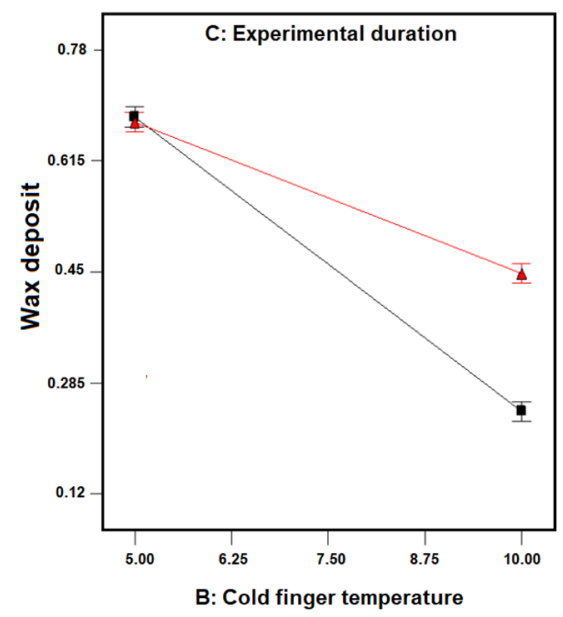

(a)

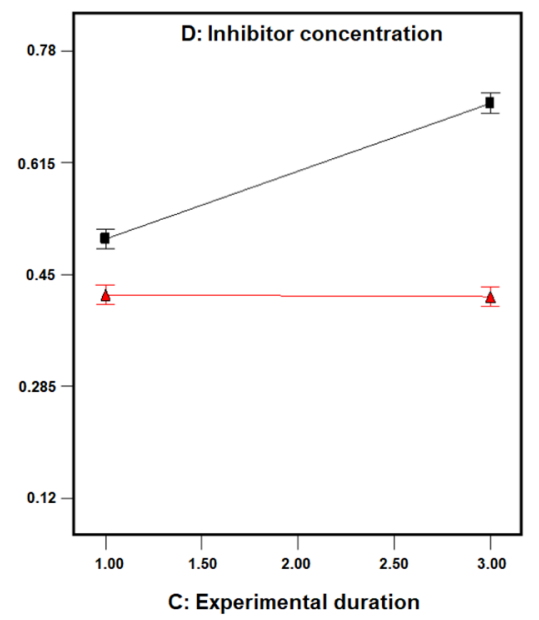

(b)

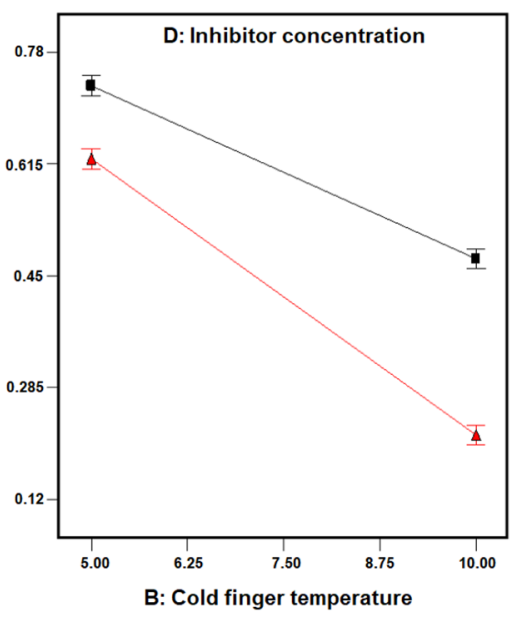

(c)

Fig. 7 Interactions between factors on wax deposit, $\mathbf{a} \mathrm{BC}, \mathbf{b} \mathrm{CD}$, and $\mathbf{c} \mathrm{BD}$ 
the experimental duration is much longer against the ageing impact. The maximum contribution percentage indicates that $\mathrm{BC}$ interaction has a major influence on wax deposit formation, followed by $\mathrm{CD}$ and $\mathrm{BD}$ interaction.

Figure $7 \mathrm{~b}$ shows the second interaction graphs between experimental duration $\mathrm{C}$ with SABA concentration $\mathrm{D}$, contributing $5.46 \%$. The inhibitor concentration was injected into crude oil to prevent the deposition of wax, as the response is used as an indicator. From this graph, D+ is selected as the best term based on the aim. Also, CD interaction will occur since both variables contribute the most to wax deposit relative to other variables. The inhibitor concentration variable contributes to increasing wax crystals at $\mathrm{D}-$ than $\mathrm{D}+$ is at $3 \mathrm{~h}$. The slope becomes less steep, suggesting that the formation of wax at $1 \mathrm{~h}$ is decreased. This also indicates that the dosage of SABA-PPD has been saturated to be effective for wax deposition reduction.

The third interaction occurred between cold finger temperature, $\mathrm{B}$, and inhibitor concentration, $\mathrm{D}$, as shown in Fig. 7c. As discussed earlier, variable B has the most significant effect since the operating temperature is below PP. In addition to D's variable influence, it is possible to minimize wax deposit formation. Experimental duration $\mathrm{C}$ contributes significantly to wax inhibition, but not as much as the influence of concentration variable inhibitor D.

\section{Conclusion}

The prediction of wax is very important in the petroleum industry because of wax accumulation in crude oil pipelines in cold regions. The experimental results show that SABA/ NP blend produces the smallest amount of wax. Therefore, the optimum conditions for reducing the amount of wax deposit have been identified using FFD at $300 \mathrm{rpm}, 10{ }^{\circ} \mathrm{C}$, $1 \mathrm{~h}, 1200 \mathrm{ppm}$, and $400 \mathrm{ppm}$, respectively, and the least amount of wax deposit was $0.12 \mathrm{~g}$ at these conditions. The variance analysis (ANOVA) has detected the value of $\mathrm{R}^{2}$ to be 0.9876 ; this represents that the model can clarify $98.76 \%$ of the data variation. The Lack of fit is not important in comparison with the pure error, which is good. The Lack of fit $F$ value of 12.85 means that there is only a $7.41 \%$ probability that this huge can occur because of noise. Therefore, it indicated that the model is highly significant, which confirmed a strong agreement among the experimental and expected wax values deposited. The temperature of the cold finger (B) was observed as the most affecting variable of wax deposition. Moreover, $\mathrm{BC}, \mathrm{CD}$, and $\mathrm{BD}$ were the most significant interactions that strongly contributed to wax deposition. Therefore, the optimum factors of the extraction from FFD will be used in the future study using Central Composite Design (CCD).
Acknowledgements The authors would like to thank the Universiti Malaysia Pahang for laboratory facilities and additional financial support under an internal research grant with reference code (RDU200302). We also thank Petronas Penapisan Terengganu, Malaysia, for providing crude oil samples for the research project.

Funding This research project was funded by University Malaysia Pahang through RDU200302 scheme.

\section{Declarations}

Conflict of interest On behalf of all authors, the corresponding author states that there is no conflict of interest.

Open Access This article is licensed under a Creative Commons Attribution 4.0 International License, which permits use, sharing, adaptation, distribution and reproduction in any medium or format, as long as you give appropriate credit to the original author(s) and the source, provide a link to the Creative Commons licence, and indicate if changes were made. The images or other third party material in this article are included in the article's Creative Commons licence, unless indicated otherwise in a credit line to the material. If material is not included in the article's Creative Commons licence and your intended use is not permitted by statutory regulation or exceeds the permitted use, you will need to obtain permission directly from the copyright holder. To view a copy of this licence, visit http://creativecommons.org/licenses/by/4.0/.

\section{References}

Alnaimat F, Ziauddin M (2020) Wax deposition and prediction in petroleum pipelines. J Petrol Sci Eng 184:106385

Chala GT, Sulaiman SA, Japper-Jaafar A, Abdullah WAKW, Mokhtar MMM (2014) Gas void formation in statically cooled waxy crude oil. Int J Therm Sci 86:41-47

Elarbe B, Ridzuan N, Yusoh K, Elganidi I, Abdullah N (2019) Screening of the factors for novel pour point depressant copolymer synthesis to improve the copolymer yield. Paper presented at the IOP Conf Ser: Mater Sci Eng 702:012028

Elarbe B, Elganidi I, Ridzuan N, Abdullah N, Yusoh K Influence of poly (stearyl acrylate co-behenyl acrylate) as flow improvers on the viscosity reduction of Malaysian crude oil. Mater Today Proc 42(1):201-210

Elganidi I, Elarbe B, Abdullah N, Ridzuan N (2020) Synthesis of a novel terpolymer of (BA-co-SMA-co-MA) as pour point depressants to improve the flowability of the Malaysian crude oil. Mater Today Proc 42:28-32

Fakoya MF, Shah SN (2017) Emergence of nanotechnology in the oil and gas industry: emphasis on the application of silica nanoparticles. Petrol 3(4):391-405

Fan K, Li S, Li R (2021) Development of wax molecular diffusivity correlation suitable for crude oil in wax deposition: Experiments with a cold-finger apparatus. J Petrol Sci Eng 205:108851

Feng L, Zhang Z, Wang F, Wan T, Yang S (2014) Synthesis and evaluation of alkyl acrylate-vinyl acetate-maleic anhydride terpolymers as cold flow improvers for diesel fuel. Fuel Proc Technol 118:42-48

Ghosh P, Hoque M, Karmakar G, Das MK (2017) Dodecyl methacrylate and vinyl acetate copolymers as viscosity modifier and pour point depressant for lubricating oil. Int J Indust Chemist 8(2):197-205 
Gürgen S (2020) Numerical modeling of fabrics treated with multiphase shear thickening fluids under high velocity impacts. ThinWalled Struc 148:106573

Handayani D, Rachma A, Marliyana S (2019) Synthesis of copoly(eugenol-stearyl acrylate) via cationic polymerization. J Physics: Conf Ser 1153:012124

Jennings DW, Weispfennig K (2005) Effects of shear and temperature on wax deposition: Coldfinger investigation with a Gulf of Mexico crude oil. Energy Fuels 19(4):1376-1386

Junyi K, Hasan N (2018) Review of the Factors that Influence the Condition of Wax Deposition in Subsea Pipelines. Int J Eng Mater Manuf 3(1):1-8

Koocheki A, Taherian AR, Razavi SM, Bostan A (2009) Response surface methodology for optimization of extraction yield, viscosity, hue and emulsion stability of mucilage extracted from Lepidium perfoliatum seeds. Food Hydrocol 23(8):2369-2379

Le Man H, Behera S, Park H (2010) Optimization of operational parameters for ethanol production from Korean food waste leachate. Int J Enviro Sci Technol 7(1):157-164

Li W, Li H, Da H, Hu K, Zhang Y, Teng L (2021) Influence of pour point depressants (PPDs) on wax deposition: a study on wax deposit characteristics and pipeline pigging. Fuel Proc Technol 217:106817

Lim ZH, Al Salim HS, Ridzuan N, Nguele R, Sasaki K (2018) Effect of surfactants and their blend with silica nanoparticles on wax deposition in a Malaysian crude oil. Petrol Sci 15(3):577-590

Lim ZH, Al Salim HS, Hasiholan B, Ridzuan N (2019) Evaluation of silane-based surfactant nanohybrid as flow improver in a Malaysian light crude oil. IOP Conf Ser Mater Sci Eng 469:012001

Litvinets IV, Prozorova IV, Yudina NV, Kazantsev OA, Sivokhin AP (2016) Effect of ammonium-containing polyalkyl acrylate on the rheological properties of crude oils with different ratio of resins and waxes. J Petrol Sci Eng 146:96-102

Machado AL, Lucas EF, González G (2001) Poly (ethylene-co-vinyl acetate)(EVA) as wax inhibitor of a Brazilian crude oil: oil viscosity, pour point and phase behavior of organic solutions. J Petrol Sci Eng 32(2-4):159-165

Makwashi N, Zhao D, Abdulkadir M, Ahmed T, Muhammad I (2021) Study on waxy crudes characterisation and chemical inhibitor assessment. J Petrol Sci Eng 204:108734

Mehrotra AK, Ehsani S, Haj-Shafiei S, Kasumu AS (2020) A review of heat-transfer mechanism for solid deposition from "waxy" or paraffinic mixtures. Can J Chem Eng 98(12):2463-2488

Municchi F, Mellas E, Icardi M, Magninl M (2020) Modelling of wax deposition in oil pipes: a dispersed multiphase turbulent flow approach. 14th Int Conf on CFD in 6 Oil and Gas, Metallu Proc Indus SINTEF

Öztürk N, Kavak D (2008) Boron removal from aqueous solutions by batch adsorption onto cerium oxide using full factorial design. Desalination 223(1-3):106-112

Paramashivaiah B, Rajashekhar C (2016) Studies on effect of various surfactants on stable dispersion of graphene nano particles in simarouba biodiesel. IOP Conf Ser Mater Sci Eng 149:012083

Rai A, Mohanty B, Bhargava R (2016) Supercritical extraction of sunflower oil: a central composite design for extraction variables. Food Chem 192:647-659

Ridzuan N, Al-Mahfadi M (2017) Evaluation on the effects of wax inhibitor and optimization of operating parameters for wax deposition in Malaysian crude oil. Petrol Sci Technol 35(20):1945-1950

Ridzuan N, Adam F, Yaacob Z (2016) Screening of factor influencing wax deposition using full factorial experimental design. Petrol Sci Technol 34(1):84-90

Ridzuan N, Subramanie P, Uyop M (2020c) Effect of pour point depressant (PPD) and the nanoparticles on the wax deposition, viscosity and shear stress for Malaysian crude oil. Petrol Sci Technol 38(20):929-935

Ridzuan N, Azhar A, Subramanie P (2020a) Evaluation on the factors influencing the deposition of wax using full factorial design. IOP Conf Ser Mater Sci Eng 736(2):022023

Ridzuan N, Subramanie P, Elarbe B, Elganidi I, Kumar S (2020b) Screening and interaction study of the operating parameter influence the wax formation using design of experiment. IOP Conf Ser Mater Sci Eng 736(2):022116

Salam K, Arinkoola A, Oke E, Adeleye J (2014) Optimization of operating parameters using response surface methodology for paraffinwax deposition in pipeline. Petrol Coal 56(1):19-28

Song X, Yin H, Feng Y, Zhang S, Wang Y (2016) Effect of SiO2 nanoparticles on wax crystallization and flow behavior of model crude oil. Ind Eng Chemis Res 55(23):6563-6568

Subramanie PA, Padhi A, Ridzuan N, Adam F (2020) Experimental study on the effect of wax inhibitor and nanoparticles on rheology of Malaysian crude oil. J King Saud Univ Eng Sci 32(8):479-483

Sun G, Zhang J, Ma C, Wang X (2016) Start-up flow behavior of pipelines transporting waxy crude oil emulsion. J Petrol Sci Eng 147:746-755

Sun X, Zhang Y, Chen G, Gai Z (2017) Application of nanoparticles in enhanced oil recovery: a critical review of recent progress. Energies 10(3):345

Tu Z, Jing G, Sun Z, Zhen Z, Li W (2017) Effect of nanocomposite of attapulgite/EVA on flow behavior and wax crystallization of model oil. J Disper Sci Technol 39(9):1280-1284

Vakili S, Mohammadi S, Derazi A M, Alemi F M, Hayatizadeh N, Ghanbarpour O, Rashidi F (2021) Effect of metal oxide nanoparticles on wax formation, morphology, and rheological behavior in crude oil: An experimental study. J Mol Liq 343:117566

VijayaKumar S, Zakaria J, Ridzuan N (2021) The role of Gemini surfactant and $\mathrm{SiO} 2 / \mathrm{SnO} / \mathrm{Ni} 2 \mathrm{O} 3$ nanoparticles as flow improver of Malaysian crude oil. J King Saud Univ Eng Sci

Wang Z, Yu X, Li J, Wang J, Zhang L (2016) The use of biobased surfactant obtained by enzymatic syntheses for wax deposition inhibition and drag reduction in crude oil pipelines. Catalysts 6(5):61

Yang F, Paso K, Norrman J, Li C, Oschmann H, Sjöblom J (2015) Hydrophilic nanoparticles facilitate wax inhibition. Energy Fuels 29(3):1368-1374

Yang F, Cheng L, Liu H, Yao B, Li C, Sun G, Zhao Y (2018) Comblike polyoctadecyl acrylate (POA) wax inhibitor triggers the formation of heterogeneous waxy oil gel deposits in a cylindrical couette device. Energy Fuels 32(1):373-383

Yao B, Li C, Zhang X, Yang F, Sun G, Zhao Y (2018) Performance improvement of the ethylene-vinyl acetate copolymer (EVA) pour point depressant by small dosage of the amino-functionalized polymethylsilsesquioxane (PAMSQ) microsphere. Fuel 220:167-176

Zhang X, Huang Q, Zhang Y, Gao X, Chen W (2021) Predicting the yield stress of oil-wax gels with long-chained n-alkanes. J Petrol Sci Eng 14:109238

Zhu X, Gu Y, Chen G, Cheng Z, Lu J (2004) Synthesis of poly (octadecyl acrylate-b-styrene-b-octadecyl acrylate) triblock copolymer by atom transfer radical polymerization. J Appl Polym Sci 93(4):1539-1545

Publisher's Note Springer Nature remains neutral with regard to jurisdictional claims in published maps and institutional affiliations. 